D. Bocharov, A. Anspoks, J. Timoshenko, A. Kalinko, M. Krack, A. Kuzmin,

Interpretation of the Cu K-edge EXAFS spectra of Cu3N using ab initio molecular dynamics,

Rad. Phys. Chem. 175 (2020) 108100.

\title{
Interpretation of the $\mathrm{Cu}$ K-edge EXAFS spectra of $\mathrm{Cu}_{3} \mathrm{~N}$ using ab initio molecular dynamics
}

\author{
Dmitry Bocharova, ${ }^{\mathrm{a}, *}$, Andris Anspoks ${ }^{\mathrm{a}}, \mathrm{Janis} \mathrm{Timoshenko}^{\mathrm{b}}$, Aleksandr Kalinko ${ }^{\mathrm{c}}$, \\ Matthias Krack ${ }^{\mathrm{d}}$, Alexei Kuzmin ${ }^{\mathrm{a}}$ \\ ${ }^{a}$ Institute of Solid State Physics, University of Latvia, Kengaraga street 8, LV-1063 Riga, Latvia \\ ${ }^{b}$ Department of Materials Science and Chemical Engineering, Stony Brook University, Stony Brook, New \\ York 11794, USA \\ ${ }^{c}$ Department Chemie, Naturwissenschaftliche Fakultät, Universität Paderborn, Warburger Strasse 100, \\ 33098 Paderborn, Germany \\ ${ }^{d}$ Paul Scherrer Institut, Forschungsstrasse 111, 5232 Villigen PSI, Switzerland
}

\begin{abstract}
Cubic copper nitride $\left(\mathrm{Cu}_{3} \mathrm{~N}\right)$ has anti-perovskite structure, and its properties are strongly affected by anisotropic thermal vibrations of copper atoms. Ab initio molecular dynamics (AIMD) simulations were performed in the temperature range from $300 \mathrm{~K}$ to $700 \mathrm{~K}$ in order to probe the details of $\mathrm{Cu}_{3} \mathrm{~N}$ lattice dynamics. The $\mathrm{Cu}$ K-edge extended X-ray absorption fine structure (EXAFS) spectrum of bulk $\mathrm{Cu}_{3} \mathrm{~N}$ was used to validate AIMD simulations at $300 \mathrm{~K}$. The AIMD results suggest strong anharmonicity of the $\mathrm{Cu}-\mathrm{N}$ and $\mathrm{Cu}-\mathrm{Cu}$ bonds, the rigidity of $\mathrm{NCu}_{6}$ octahedra and strong correlation in atomic motion within $-\mathrm{N}-\mathrm{Cu}-\mathrm{N}-$ atom chains as well as support anisotropy of copper thermal vibrations.
\end{abstract}

Keywords: Copper nitride, $\mathrm{Cu}_{3} \mathrm{~N}$, Extended $\mathrm{X}$-ray absorption fine structure (EXAFS), Ab initio molecular dynamics

\footnotetext{
${ }^{*}$ Corresponding author

E-mail address: bocharov@ latnet.lv (Dmitry Bocharov).
} 


\section{Introduction}

Copper nitride $\left(\mathrm{Cu}_{3} \mathrm{~N}\right)$ has a cubic anti- $\mathrm{ReO}_{3}$-type structure (Fig. 1) composed of the $\mathrm{NCu}_{6}$ octahedra joined by corners (Zachwieja and Jacobs, 1990; Paniconi et al., 2007). Opposite to metallic $\mathrm{ReO}_{3}$, pure $\mathrm{Cu}_{3} \mathrm{~N}$ is a narrow band gap $\left(E_{g}=1.1-1.8 \mathrm{eV}\right)$ semiconductor (Jiang et al., 2018). $\mathrm{Cu}_{3} \mathrm{~N}$ is potentially interesting candidate for many applications such as write-once read-many (WORM) optical storage devices (Asano et al., 1990; Maruyama and Morishita, 1996), non-volatile magnetic random access memories (Borsa et al., 2002) and optical lithography for a fabrication of microscopic metal links (Maya, 1993; Borsa and Boerma, 2004). Electro-catalytic properties of copper nitride in alkaline fuel cells were also reported (Wu and Chen, 2011). $\mathrm{Cu}_{3} \mathrm{~N}$ usage as an absorber for photovoltaic and photo-electrochemical solar cells was recently reported (Zakutayev et al., 2014; Caskey et al., 2014).

The dynamic properties of $\mathrm{Cu}_{3} \mathrm{~N}$ lattice are determined by anisotropic thermal vibrations of copper atoms, having larger amplitude orthogonal to linear $-\mathrm{N}-\mathrm{Cu}-\mathrm{N}-$ atomic chains (Zachwieja and Jacobs, 1990). X-ray absorption spectroscopy is ideally suited to probe in-situ local atomic structure and lattice dynamics of $\mathrm{Cu}_{3} \mathrm{~N}$ (Kuzmin et al., 2016b; Timoshenko et al., 2017). It was shown previously based on the results of reverse Monte Carlo calculations (Timoshenko et al., 2016, 2017) that the anisotropy of copper atom vibrations is enhanced upon increasing temperature and is accompanied by tilting motion of $\mathrm{NCu}_{6}$ octahedra. Strong correlation in the motion of atoms was observed along $-\mathrm{N}-\mathrm{Cu}-\mathrm{N}-$ atomic chains but it reduced with an increase of interatomic distance. Finally, it was found that anticorrelated motion of nearest $\mathrm{Cu}$ atoms indicates on breathing-type motion of $\mathrm{NCu}_{6}$ octahedra.

Another atomistic simulation approach to the interpretation of EXAFS utilizes molecular dynamics (MD) simulations (D’Angelo et al., 1994, 1996; Palmer et al., 1996). The MD-EXAFS method is especially useful for the analysis of EXAFS in crystalline materials where outer shell and multiple-scattering (MS) contributions are significant and overlap (Kuzmin and Evarestov, 2009; Kuzmin et al., 2016a; Bocharov et al., 2016). Besides, the method can be employed to validate the interatomic potential models used in the classical MD simulations (Kuzmin et al., 2016a; Bocharov et al., 
2017).

In the MD-EXAFS method, the structural model of a material is constructed first, taking into account periodicity, chemical composition as well as the particle size and shape in the case of nanomaterials. One should also define the interaction potential model, which can be based on empirical force-field or calculated from first-principles. Next, the MD simulation is performed at the required temperature and pressure, providing a set of instantaneous atomic configurations ("snapshots"), which represent a time-dependent evolution of the material structure. The use of Newtonian dynamics restricts the application of MD at low temperatures, where the quantum zero-point motion of atoms becomes important. Nevertheless, MD method usually performs well at high temperatures and, thus, is suitable to model the anharmonic thermal motion of atoms. When the MD simulation is done, the accumulated coordinates of atoms can be used to evaluate different structural properties as, for example, the radial distribution functions, the mean interatomic distances and angles, the mean-square relative displacements, etc. Moreover, a set of EXAFS spectra can be calculated for each of the atomic configurations within ab initio MS formalism, and the configuration-averaged EXAFS spectrum can be readily compared with the experiment to validate the MD simulation.

The MD-EXAFS approach, based on classical MD simulations, has been successfully applied previously to a number of perovskite-type materials as $\mathrm{SrTiO}_{3}$ (Kuzmin and Evarestov, 2009; Kuzmin et al., 2016a), $\mathrm{ReO}_{3}$ (Kalinko et al., 2009), $\mathrm{LaCoO}_{3}$ (Kuzmin et al., 2011) and $\mathrm{ScF}_{3}$ (Bocharov et al., 2016). Some preliminary results have been also obtained for $\mathrm{Cu}_{3} \mathrm{~N}$ (Timoshenko et al., 2016).

In this study, we performed systematic ab initio molecular dynamics (AIMD) simulations of bulk $\mathrm{Cu}_{3} \mathrm{~N}$ in the temperature range from $300 \mathrm{~K}$ to $700 \mathrm{~K}$ in order to elucidate the details of lattice dynamics and anharmonicity of the $\mathrm{Cu}-\mathrm{N}$ and $\mathrm{Cu}-\mathrm{Cu}$ bonding.

\section{Experimental}

The room temperature $\mathrm{Cu}$ K-edge X-ray absorption spectrum (Fig. 2) of commercial polycrystalline $\mathrm{Cu}_{3} \mathrm{~N}$ powder $(99.5 \%$, Alfa Aesar) was acquired in transmission 
D. Bocharov, A. Anspoks, J. Timoshenko, A. Kalinko, M. Krack, A. Kuzmin, Interpretation of the Cu K-edge EXAFS spectra of Cu3N using ab initio molecular dynamics, Rad. Phys. Chem. 175 (2020) 108100.

mode at the bending magnet beamline C (Rickers et al., 2007) at HASYLAB/DESY synchrotron radiation facility. The details of the experiment and data treatment were published previously (Kuzmin et al., 2016b; Timoshenko et al., 2017).

\section{Computational details}

The AIMD simulations of bulk $\mathrm{Cu}_{3} \mathrm{~N}$ were performed based on Kohn-Sham density functional theory (DFT) within the isobaric-isothermal (NpT) ensemble. The QuicksteP module (VandeVondele et al., 2005) of the CP2K code (CP2K developers group, 2000-2018) was employed for all AIMD runs using the Cray XC50 system "Piz Daint" at the Swiss National Supercomputing Centre (CSCS). Goedecker-Teter-Hutter (GTH) pseudopotentials (semi-core GTH PP for Cu) (Krack, 2005) and contracted Gaussian basis sets of double-zeta quality specifically optimised for the use with the GTH pseudopotentials in the framework of CP2K for condensed phase systems (DZVP, MOLOPT-SR) (VandeVondele and Hutter, 2007) were employed in all runs.

NpT ensemble AIMD was conducted at four temperatures: 300, 450, 600, and $700 \mathrm{~K}$. A thermalisation run of about 15 ps duration was performed at each temperature to equilibrate the supercell $5 a_{0} \times 5 a_{0} \times 5 a_{0}\left(a_{0}=3.819 \AA\right.$ is the lattice parameter $) \mathrm{Cu}_{3} \mathrm{~N}$ model system with periodic boundary conditions at the actual target temperature. This supercell size is large enough to avoid artefacts in the EXAFS spectra during the MDEXAFS analysis (Kuzmin and Evarestov, 2009) in the post-processing phase. Finally, the equilibrated systems were used in the production runs of about 30 ps duration at the each target temperature.

Sets of atomic coordinates obtained as a result of the AIMD simulations were used to calculate the radial distribution functions (RDFs) and the mean-square relative displacements (MSRD) (also known as Debye-Waller factors) for $\mathrm{Cu}-\mathrm{N}$ and $\mathrm{Cu}-\mathrm{Cu}$ atom pairs. The average bond angles and the bond angles between the average positions of $\mathrm{Cu}$ and $\mathrm{N}$ atoms were also evaluated.

Sets of atomic configurations obtained in the AIMD simulations were used to calculate the configuration-averaged $\mathrm{Cu}$ K-edge EXAFS $\chi(k)(k$ is the photoelectron wavenumber) within the multiple-scattering (MS) approach (Kuzmin and Evarestov, 
D. Bocharov, A. Anspoks, J. Timoshenko, A. Kalinko, M. Krack, A. Kuzmin, Interpretation of the Cu K-edge EXAFS spectra of Cu3N using ab initio molecular dynamics, Rad. Phys. Chem. 175 (2020) 108100.

2009; Kuzmin et al., 2016a) using ab initio self-consistent real-space MS FEFF8.50L code (Ankudinov et al., 1998; Rehr and Albers, 2000). The scattering potential and partial phase shifts were calculated only once for the cluster with the radius of $8 \AA$, centered at the absorbing $\mathrm{Cu}$ atom and constructed based on the crystallographic $\mathrm{Cu}_{3} \mathrm{~N}$ structure. The photoelectron inelastic losses were accounted using the complex exchangecorrelation Hedin-Lundqvist potential (Hedin and Lundqvist, 1971).

\section{Results}

The experimental and calculated (using NpT ensemble AIMD) Cu K-edge EXAFS spectra of bulk $\mathrm{Cu}_{3} \mathrm{~N}$ at $300 \mathrm{~K}$ and their Fourier transforms (FTs) are compared in Fig. 2. The overall agreement between theory and experiment is quite good. The frequency of the EXAFS signals and the related positions of peaks in FTs are well reproduced by the simulations. However, the amplitudes of the FT peaks at $2.3 \AA$ and $3.4 \AA$ are larger in the simulated signal indicating that thermal disorder is underestimated in the second and third coordination shells.

Atomic configurations produced in the AIMD simulations of $\mathrm{Cu}_{3} \mathrm{~N}$ can be used to extract a number of structural parameters and their temperature dependencies.

In Fig. 3 the calculated radial distribution functions (RDFs) $G(R)$ around the absorbing atom $\mathrm{Cu}_{0}$ are shown in the region of the nearest two shells, corresponding to $\mathrm{Cu}_{0}-\mathrm{N}_{1}$ and $\mathrm{Cu}_{0}-\mathrm{Cu}_{2}$ atom pairs. The asymmetric shape of the two peaks at $\sim 1.9 \AA$ and $\sim 2.7 \AA$ suggests a strong anharmonicity of the atomic vibrations in $\mathrm{Cu}_{3} \mathrm{~N}$.

The temperature dependencies of the mean-square relative displacements (MSRD) for the first seven coordination shells of the absorbing $\mathrm{Cu}_{0}$ atom are shown in Fig. 4 for $\mathrm{Cu}-\mathrm{N}$ and $\mathrm{Cu}-\mathrm{Cu}$ atom pairs. The results of reverse Monte Carlo (RMC) analysis of low-temperature (10-300 K) EXAFS data are also given for comparison (Timoshenko et al., 2017). The two sets of MSRD data match each other at $300 \mathrm{~K}$. The temperature dependencies of the MSRD factors for $\mathrm{Cu}_{0}-\mathrm{N}_{1}, \mathrm{Cu}_{0}-\mathrm{N}_{4}, \mathrm{Cu}_{0}-\mathrm{Cu}_{2}$ and $\mathrm{Cu}_{0}-\mathrm{Cu}_{6}$ atom pairs agree well between low-temperature experimental and high-temperature calculated values. At the same time, the AIMD calculated MSRD factors for $\mathrm{Cu}_{0}-\mathrm{N}_{7 b}$, $\mathrm{Cu}_{0}-\mathrm{Cu}_{3 b}$ and $\mathrm{Cu}_{0}-\mathrm{Cu}_{5}$ atom pairs are overestimated, but for $\mathrm{Cu}_{0}-\mathrm{N}_{7 a}$ and $\mathrm{Cu}_{0}-\mathrm{Cu}_{3 b}$ 
atom pairs are slightly underestimated. Thus, overall, the AIMD calculations are able to describe the structure and dynamics of bulk $\mathrm{Cu}_{3} \mathrm{~N}$.

It is important that analysis of atomic coordinates allows us to separate atom pairs having similar interatomic distances as $\mathrm{Cu}_{0}-\mathrm{N}_{7 a}$ and $\mathrm{Cu}_{0}-\mathrm{N}_{7 b}$ or $\mathrm{Cu}_{0}-\mathrm{Cu}_{3 a}$ and $\mathrm{Cu}_{0}-$ $\mathrm{Cu}_{3 b}$ (Fig. 1). Small values of MSRDs for $\mathrm{Cu}-\mathrm{N}_{1}, \mathrm{Cu}-\mathrm{Cu}_{3 a}$ and $\mathrm{Cu}-\mathrm{N}_{7 a}$ atom pairs relative to others suggest strong correlation in atomic motion along crystallographic axes within $-\mathrm{Cu}-\mathrm{N}-\mathrm{Cu}-\mathrm{N}-$ atomic chains. Moreover, the MSRD factors for $\mathrm{Cu}_{0}-\mathrm{Cu}_{3 b}$ are much larger than those for $\mathrm{Cu}_{0}-\mathrm{Cu}_{3 a}$ indicating anisotropic thermal vibration of $\mathrm{Cu}$ atoms, with the amplitude being larger in the direction orthogonal to $-\mathrm{N}-\mathrm{Cu}-\mathrm{N}-$ chains.

Temperature dependencies of several bond angles are shown in Figs. 5, 6 and 7. Here we distinguish between the average values of bond angles $(\langle\rangle)$, seen by EXAFS, and the angle values between the average positions of atoms $(\langle\rangle-\langle\rangle-\langle\rangle)$, seen by diffraction. A strong difference between these two cases was observed for $\mathrm{N}_{1}-\mathrm{Cu}_{3 a}-\mathrm{N}_{7 a}$, $\mathrm{Cu}_{0}-\mathrm{N}_{1}-\mathrm{Cu}_{3 a}$ and $\mathrm{Cu}_{0}-\mathrm{Cu}_{2}-\mathrm{Cu}_{6}$ angles, whereas no or very small difference was detected for $\mathrm{Cu}_{0}-\mathrm{N}_{1}-\mathrm{Cu}_{2}$ and $\mathrm{Cu}_{0}-\mathrm{Cu}_{2}-\mathrm{Cu}_{3 a}$ angles.

The anisotropic vibrational amplitude of $\mathrm{Cu}$ atoms is responsible for a decrease of the average values of $\mathrm{N}_{1}-\mathrm{Cu}_{3 a}-\mathrm{N}_{7 a}$ and $\mathrm{Cu}_{0}-\mathrm{N}_{1}-\mathrm{Cu}_{3 a}$ angles by about 5-15. At the same time, the rigidity of $\mathrm{NCu}_{6}$ octahedra is supported by a stability of $\mathrm{Cu}_{0}-\mathrm{N}_{1}-\mathrm{Cu}_{2}$ and $\mathrm{Cu}_{0}-\mathrm{Cu}_{2}-\mathrm{Cu}_{3 a}$ angles being close to $90^{\circ}$. Finally, a dynamical tilting of $\mathrm{NCu}_{6}$ octahedra can be deduced from a behaviour of $\mathrm{Cu}_{0}-\mathrm{Cu}_{2}-\mathrm{Cu}_{6}$ angle together with the large MSRD for $\mathrm{Cu}_{0}-\mathrm{Cu}_{3 b}$.

\section{Conclusion}

$\mathrm{Ab}$ initio molecular dynamics simulations of cubic anti-perovskite copper nitride were performed within the $\mathrm{NpT}$ ensemble in the temperature range between 300 and $700 \mathrm{~K}$. The AIMD results were validated using the MD-EXAFS approach by direct comparison with the $\mathrm{Cu}$ K-edge EXAFS of polycrystalline $\mathrm{Cu}_{3} \mathrm{~N}$ at $300 \mathrm{~K}$. The simulations predict strong anharmonicity of $\mathrm{Cu}-\mathrm{N}$ and $\mathrm{Cu}-\mathrm{Cu}$ bonds, anisotropy of $\mathrm{Cu}$ atoms vibrations, the rigidity of $\mathrm{NCu}_{6}$ octahedra and strong correlation in atomic mo- 
D. Bocharov, A. Anspoks, J. Timoshenko, A. Kalinko, M. Krack, A. Kuzmin,

Interpretation of the Cu K-edge EXAFS spectra of Cu3N using ab initio molecular dynamics, Rad. Phys. Chem. 175 (2020) 108100.

tion within $-\mathrm{N}-\mathrm{Cu}-\mathrm{N}-$ atom chains. These findings are in agreement with the reverse Monte Carlo analysis of low-temperature (10-300 K) EXAFS data (Timoshenko et al., 2017).

\section{Acknowledgements}

Financial support provided by project No. 1.1.1.2/VIAA/1/16/147 (1.1.1.2/16/I/001) under the activity "Post-doctoral research aid" realized at the Institute of Solid State Physics, University of Latvia is greatly acknowledged. This work was supported by a grant from the Swiss National Supercomputing Centre (CSCS) under the project ID s681.

\section{References}

Ankudinov, A.L., Ravel, B., Rehr, J.J., Conradson, S.D., 1998. Real-space multiplescattering calculation and interpretation of X-ray-absorption near-edge structure. Phys. Rev. B 58, 7565-7576. doi:10.1103/PhysRevB.58.7565.

Asano, M., Umeda, K., Tasaki, A., 1990. $\mathrm{Cu}_{3} \mathrm{~N}$ thin film for a new light recording media. Jap. J. Appl. Phys. 29, 1985. doi:1347-4065/29/i=10R/a=1985.

Bocharov, D., Chollet, M., Krack, M., Bertsch, J., Grolimund, D., Martin, M., Kuzmin, A., Purans, J., Kotomin, E., 2017. Analysis of the $\mathrm{U} \mathrm{L}_{3}$-edge X-ray absorption spectra in $\mathrm{UO}_{2}$ using molecular dynamics simulations. Prog. Nucl. Energy 94, 187193. doi:10.1016/j.pnucene.2016.07.017.

Bocharov, D., Krack, M., Kalinko, A., Purans, J., Rocca, F., Ali, S.E., Kuzmin, A., 2016. Ab initio molecular dynamics simulations of the Sc K-edge EXAFS of scandium trifluoride. J. Phys.: Conf. Ser. 712, 012009. doi:10. 1088/1742-6596/712/ $1 / 012009$.

Borsa, D., Boerma, D., 2004. Growth, structural and optical properties of $\mathrm{Cu}_{3} \mathrm{~N}$ films. Surf. Sci. 548, 95-105. doi:10.1016/j.susc . 2003.10.053. 
D. Bocharov, A. Anspoks, J. Timoshenko, A. Kalinko, M. Krack, A. Kuzmin, Interpretation of the Cu K-edge EXAFS spectra of Cu3N using ab initio molecular dynamics, Rad. Phys. Chem. 175 (2020) 108100.

Borsa, D.M., Grachev, S., Presura, C., Boerma, D.O., 2002. Growth and properties of $\mathrm{Cu}_{3} \mathrm{~N}$ films and $\mathrm{Cu}_{3} \mathrm{~N} / \gamma /-\mathrm{Fe}_{4} \mathrm{~N}$ bilayers. Appl. Phys. Lett. 80, 1823-1825. doi:10 . 1063/1.1459116.

Caskey, C.M., Richards, R.M., Ginley, D.S., Zakutayev, A., 2014. Thin film synthesis and properties of copper nitride, a metastable semiconductor. Mater. Horiz. 1, 424430. doi:10.1039/C4MH00049H.

CP2K developers group, 2000-2018. (http://www.cp2k.org).

D’Angelo, P., Di Nola, A., Filipponi, A., Pavel, N.V., Roccatano, D., 1994. An extended x-ray absorption fine structure study of aqueous solutions by employing molecular dynamics simulations. J. Chem. Phys. 100, 985-994. doi:10.1063/1. 466581.

D’Angelo, P., Di Nola, A., Mangoni, M., Pavel, N.V., 1996. An extended x-ray absorption fine structure study by employing molecular dynamics simulations: Bromide ion in methanolic solution. J. Chem. Phys. 104, 1779-1790. doi:10.1063/1.471711.

Hedin, L., Lundqvist, S., 1971. Explicit local exchange-correlation potentials. J. Phys. C: Solid State Phys. 4, 2064. doi:10.1088/0022-3719/4/14/022.

Jiang, A., Qi, M., Xiao, J., 2018. Preparation, structure, properties, and application of copper nitride $\left(\mathrm{Cu}_{3} \mathrm{~N}\right)$ thin films: A review. J. Mater. Sci. Technol. 34, 1467-1473. doi:10.1016/j.jmst.2018.02.025.

Kalinko, A., Evarestov, R.A., Kuzmin, A., Purans, J., 2009. Interpretation of EXAFS in $\mathrm{ReO}_{3}$ using molecular dynamics simulations. J. Phys.: Conf. Ser. 190, 012080. doi:10.1088/1742-6596/190/1/012080.

Krack, M., 2005. Pseudopotentials for $\mathrm{H}$ to $\mathrm{Kr}$ optimized for gradient-corrected exchange-correlation functionals. Theor. Chem. Acc. 114, 145-152. doi:10.1007/ s00214-005-0655-y.

Kuzmin, A., Anspoks, A., Kalinko, A., Timoshenko, J., 2016a. The use of X-ray absorption spectra for validation of classical force-field models. Z. Phys. Chem. 230, 537-549. doi:10.1515/zpch-2015-0664. 
D. Bocharov, A. Anspoks, J. Timoshenko, A. Kalinko, M. Krack, A. Kuzmin, Interpretation of the Cu K-edge EXAFS spectra of Cu3N using ab initio molecular dynamics, Rad. Phys. Chem. 175 (2020) 108100.

Kuzmin, A., Efimov, V., Efimova, E., Sikolenko, V., Pascarelli, S., Troyanchuk, I., 2011. Interpretation of the Co K-edge EXAFS in $\mathrm{LaCoO}_{3}$ using molecular dynamics simulations. Solid State Ionics 188, 21-24. doi:10.1016/j.ssi . 2010.09.036.

Kuzmin, A., Evarestov, R.A., 2009. Quantum mechanics-molecular dynamics approach to the interpretation of x-ray absorption spectra. Journal of Physics: Condensed Matter 21, 055401. doi:10.1088/0953-8984/21/5/055401.

Kuzmin, A., Kalinko, A., Anspoks, A., Timoshenko, J., Kalendarev, R., 2016b. Study of copper nitride thin film structure. Latvian J. Phys. Tech. Sci. 53, 31-37. doi:10 . 1515/lpts-2016-0011.

Maruyama, T., Morishita, T., 1996. Copper nitride and tin nitride thin films for writeonce optical recording media. Appl. Phys. Lett. 69, 890-891. doi:10.1063/1. 117978.

Maya, L., 1993. Deposition of crystalline binary nitride films of tin, copper, and nickel by reactive sputtering. J. Vacuum Sci. Technol. A 11, 604-608. doi:10.1116/1. 578778.

Palmer, B.J., Pfund, D.M., Fulton, J.L., 1996. Direct modeling of exafs spectra from molecular dynamics simulations. J. Chem. Phys. 100, 13393-13398. doi:10.1021/ jp960160q.

Paniconi, G., Stoeva, Z., Doberstein, H., Smith, R.I., Gallagher, B.L., Gregory, D.H., 2007. Structural chemistry of $\mathrm{Cu}_{3} \mathrm{~N}$ powders obtained by ammonolysis reactions. Solid State Sci. 9, 907-913. doi:10.1016/j.solidstatesciences.2007.03. 017.

Rehr, J.J., Albers, R.C., 2000. Theoretical approaches to X-ray absorption fine structure. Rev. Mod. Phys. 72, 621-654. doi:10.1103/RevModPhys .72.621.

Rickers, K., Drube, W., Schulte-Schrepping, H., Welter, E., Brüggmann, U., Herrmann, M., Heuer, J., Schulz-Ritter, H., 2007. New XAFS facility for in-situ measurements at beamline C at HASYLAB. AIP Conf. Proc. 882, 905-907. doi:10.1063/1. 2644700. 
D. Bocharov, A. Anspoks, J. Timoshenko, A. Kalinko, M. Krack, A. Kuzmin,

Interpretation of the Cu K-edge EXAFS spectra of Cu3N using ab initio molecular dynamics, Rad. Phys. Chem. 175 (2020) 108100.

Timoshenko, J., Anspoks, A., Kalinko, A., Kuzmin, A., 2016. Local structure of copper nitride revealed by EXAFS spectroscopy and a reverse Monte Carlo/evolutionary algorithm approach. Phys. Scr. 91, 054003. doi:10.1088/0031-8949/91/5/ 054003.

Timoshenko, J., Anspoks, A., Kalinko, A., Kuzmin, A., 2017. Thermal disorder and correlation effects in anti-perovskite-type copper nitride. Acta Mater. 129, 61-71. doi:10.1016/j.actamat.2017.02.074.

VandeVondele, J., Hutter, J., 2007. Gaussian basis sets for accurate calculations on molecular systems in gas and condensed phases. J. Chem. Phys. 127, 114105. doi:10.1063/1.2770708.

VandeVondele, J., Krack, M., Mohamed, F., Parrinello, M., Chassaing, T., Hutter, J., 2005. QuicksteP: Fast and accurate density functional calculations using a mixed Gaussian and plane waves approach. Comput. Phys. Commun. 167, 103128. doi:10.1016/j.cpc. 2004.12.014.

Wu, H., Chen, W., 2011. Copper nitride nanocubes: Size-controlled synthesis and application as cathode catalyst in alkaline fuel cells. J. Am. Chem. Soc. 133, 1523615239. doi:10.1021/ja204748u.

Zachwieja, U., Jacobs, H., 1990. Ammonothermalsynthese von kupfernitrid, $\mathrm{Cu}_{3}$ N. J. Less Common Metals 161, 175-184. doi:10.1016/0022-5088(90)90327-G.

Zakutayev, A., Caskey, C.M., Fioretti, A.N., Ginley, D.S., Vidal, J., Stevanovic, V., Tea, E., Lany, S., 2014. Defect Tolerant Semiconductors for Solar Energy Conversion. J. Phys. Chem. Lett. 5, 1117-1125. doi:10.1021/jz5001787. 

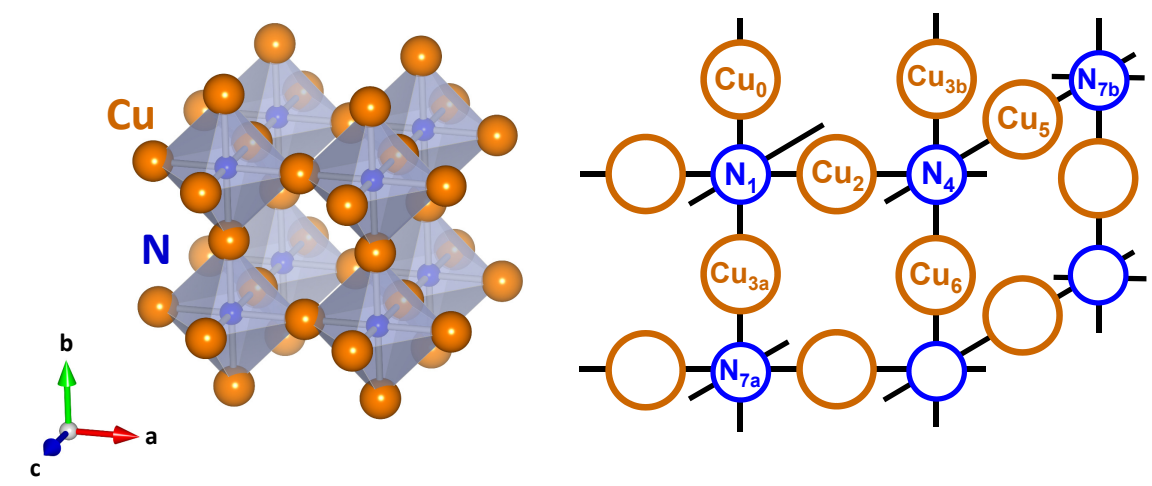

Figure 1: Crystal structure of cubic $\mathrm{Cu}_{3} \mathrm{~N}$ composed of regular $\mathrm{NCu}_{6}$ octahedra (left panel). Fragment of $\mathrm{Cu}_{3} \mathrm{~N}$ structure with the labelled atoms of the first seven coordination shells around the absorbing copper atom $\mathrm{Cu}_{0}$ (right panel). Non-equivalent atoms located at the same distance from the absorbing one are denoted by (a) and (b). 
D. Bocharov, A. Anspoks, J. Timoshenko, A. Kalinko, M. Krack, A. Kuzmin,

Interpretation of the Cu K-edge EXAFS spectra of Cu3N using ab initio molecular dynamics, Rad. Phys. Chem. 175 (2020) 108100.
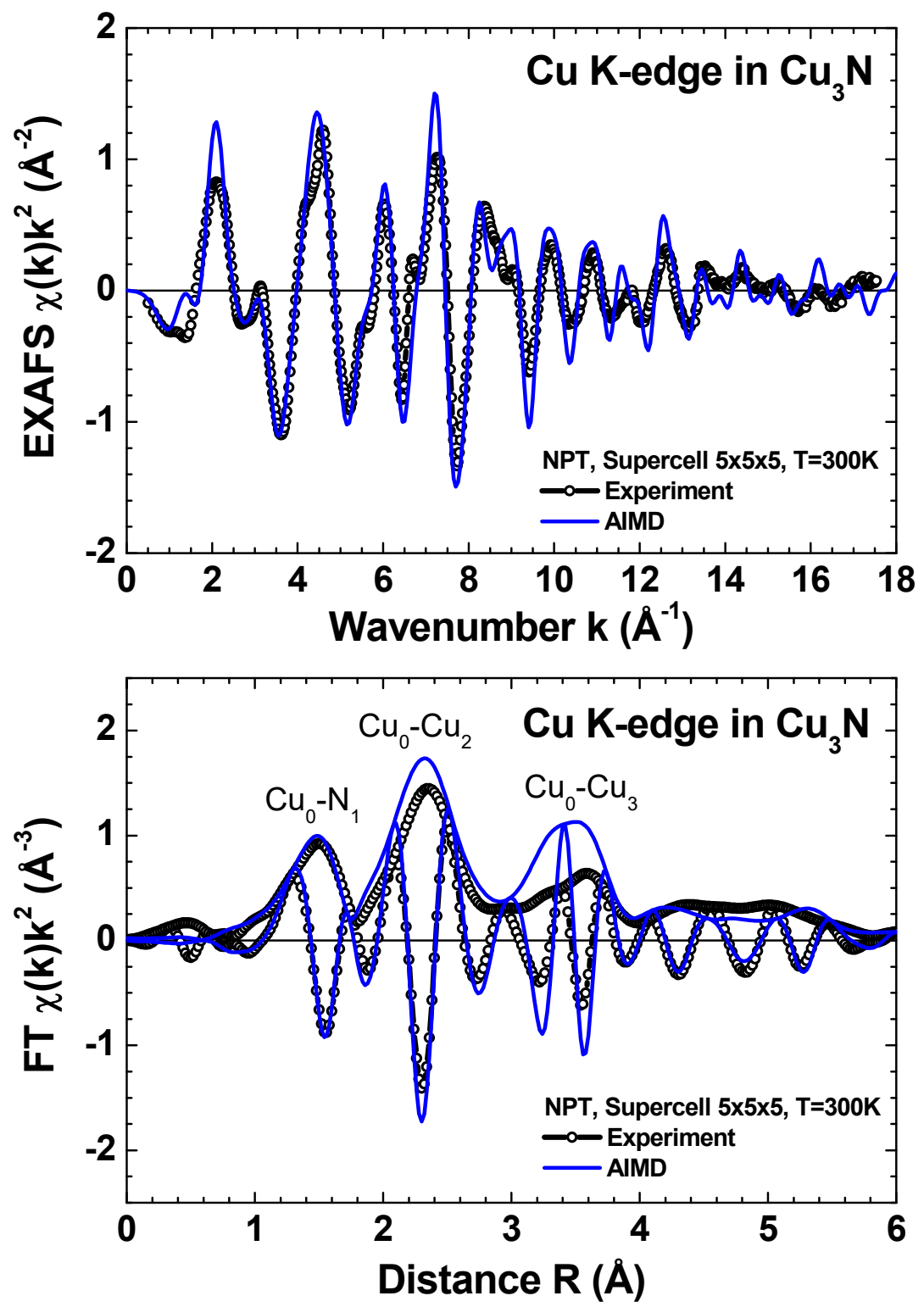

Figure 2: The experimental and AIMD calculated $\mathrm{Cu}$ K-edge EXAFS spectra (top panel) and their Fourier transforms (FTs) (bottom panel) at $300 \mathrm{~K}$. The three peaks in FTs corresponding to the three nearest coordination shells, composed of nitrogen and copper atoms are indicated. 
D. Bocharov, A. Anspoks, J. Timoshenko, A. Kalinko, M. Krack, A. Kuzmin,

Interpretation of the Cu K-edge EXAFS spectra of Cu3N using ab initio molecular dynamics, Rad. Phys. Chem. 175 (2020) 108100.

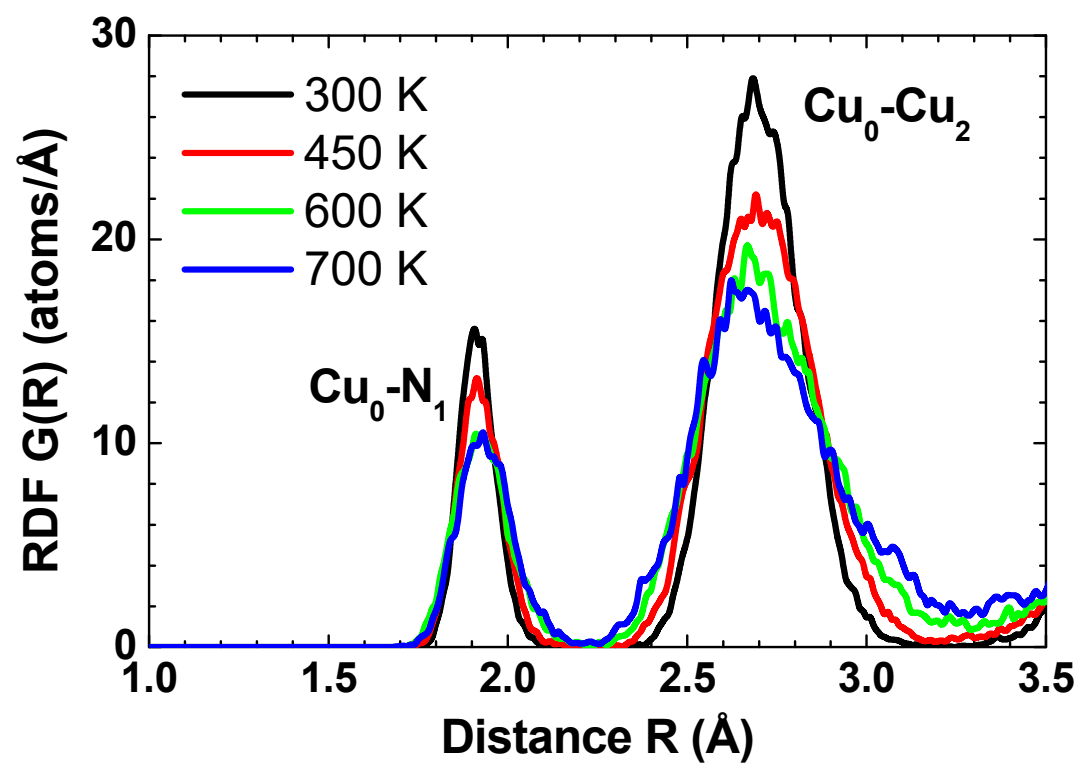

Figure 3: Temperature dependence of the radial distribution functions for $\mathrm{Cu}_{0}-\mathrm{N}_{1}$ and $\mathrm{Cu}_{0}-\mathrm{Cu}_{2}$ atom pairs obtained from AIMD simulations. Note pronounced asymmetry of both RDFs due to anharmonic lattice dynamics in $\mathrm{Cu}_{3} \mathrm{~N}$. 
D. Bocharov, A. Anspoks, J. Timoshenko, A. Kalinko, M. Krack, A. Kuzmin,

Interpretation of the Cu K-edge EXAFS spectra of Cu3N using ab initio molecular dynamics, Rad. Phys. Chem. 175 (2020) 108100.

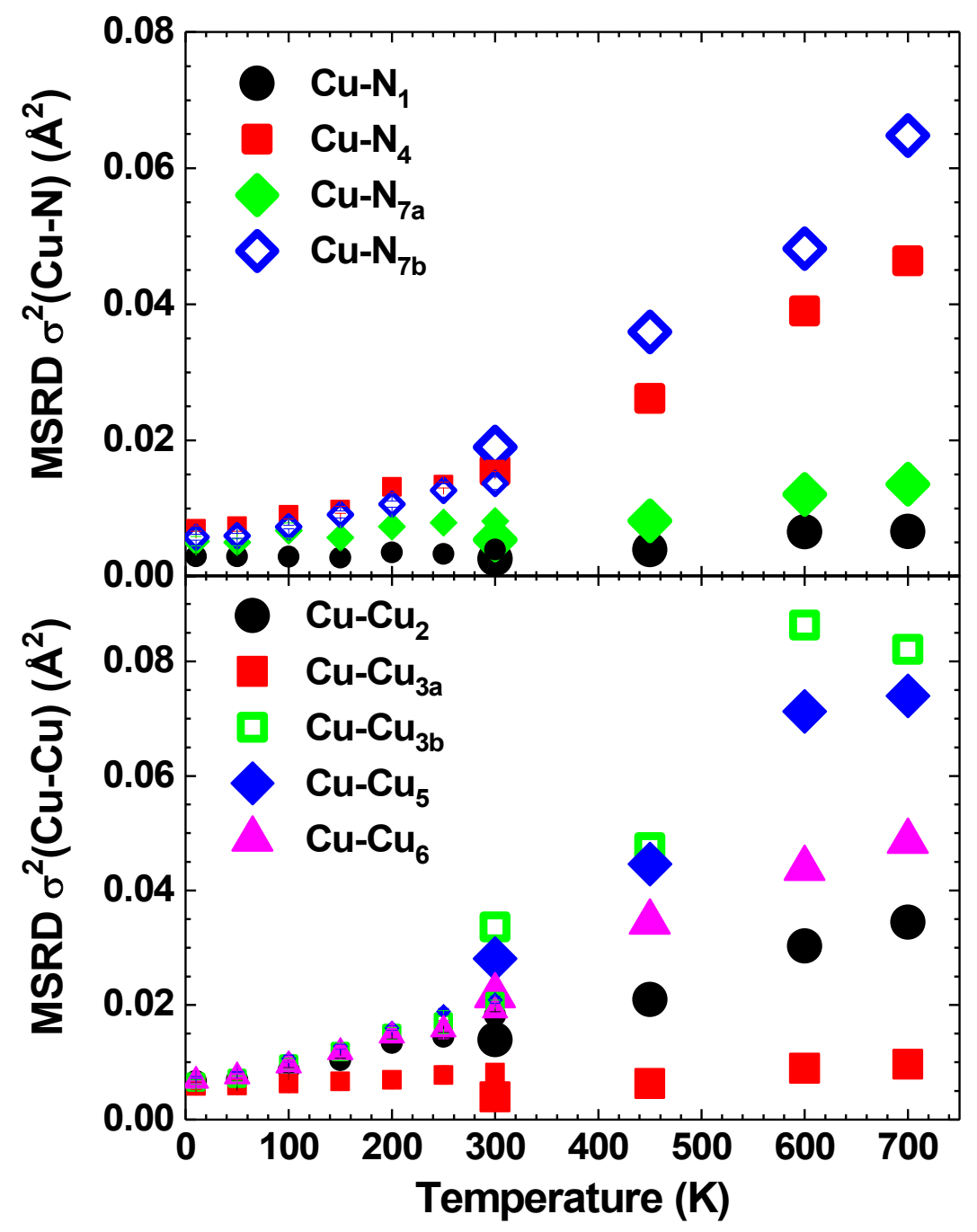

Figure 4: Temperature dependencies of the MSRD factors calculated from the results of AIMD simulations for $\mathrm{Cu}-\mathrm{N}$ (top panel) and $\mathrm{Cu}-\mathrm{Cu}$ (bottom panel) atom pairs in the first seven coordination shells around the absorbing $\left(\mathrm{Cu}_{0}\right)$ atoms at four different temperatures (300, 450, 600 and $\left.700 \mathrm{~K}\right)$. The MSRD values shown by small symbols are taken from reverse Monte Carlo analysis of low-temperature (10-300 K) EXAFS data (Timoshenko et al., 2017). 
D. Bocharov, A. Anspoks, J. Timoshenko, A. Kalinko, M. Krack, A. Kuzmin,

Interpretation of the Cu K-edge EXAFS spectra of Cu3N using ab initio molecular dynamics,

Rad. Phys. Chem. 175 (2020) 108100.

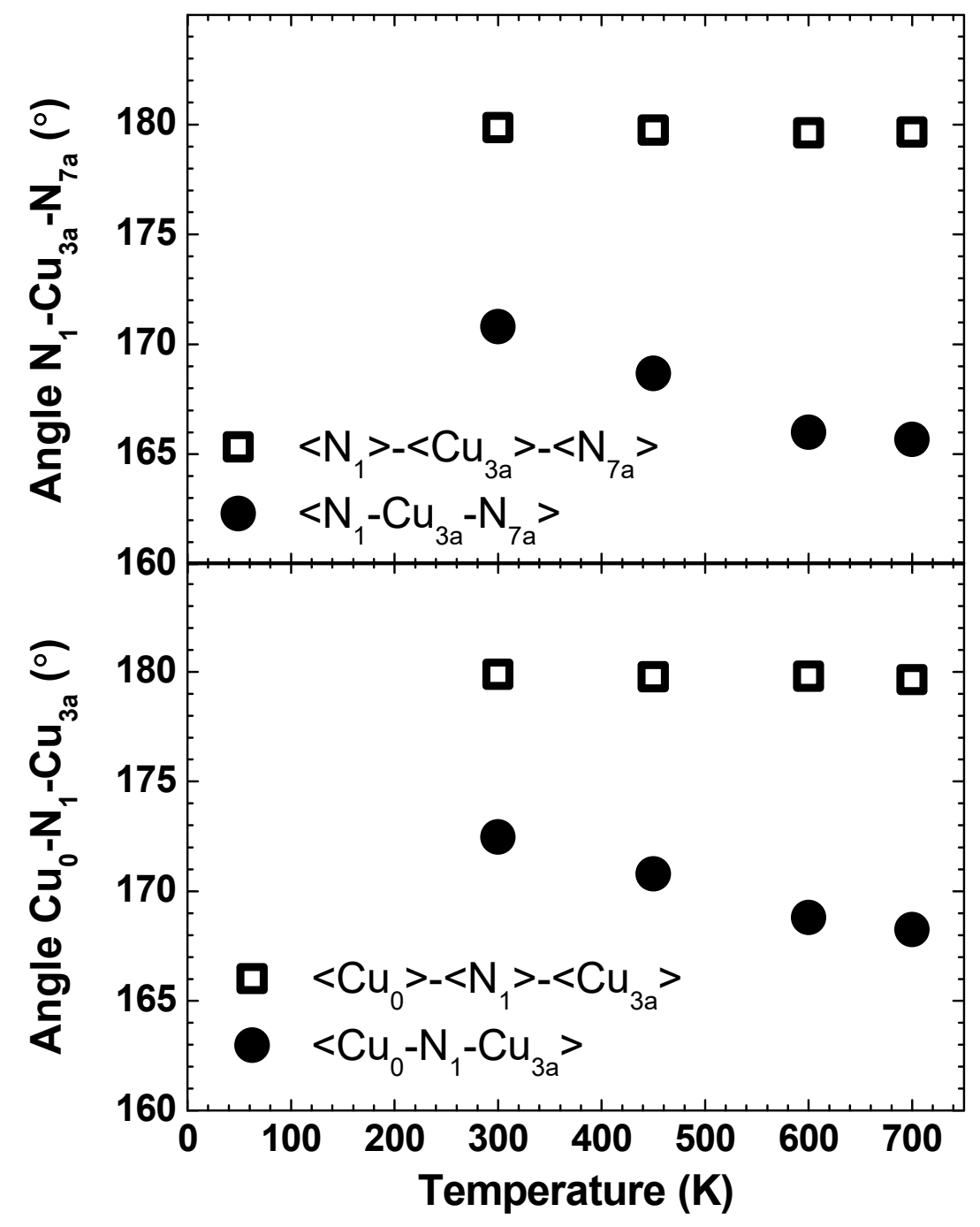

Figure 5: Temperature dependencies of the $\mathrm{N}_{1}-\mathrm{Cu}_{3 a}-\mathrm{N}_{7 a}$ and $\mathrm{Cu}_{0}-\mathrm{N}_{1}-\mathrm{Cu}_{3 a}$ bond angle values in $\mathrm{Cu}_{3} \mathrm{~N}$ system. Open squares are angles between the average positions of atoms, whereas solid circles correspond to the average angles. 
D. Bocharov, A. Anspoks, J. Timoshenko, A. Kalinko, M. Krack, A. Kuzmin,

Interpretation of the Cu K-edge EXAFS spectra of Cu3N using ab initio molecular dynamics, Rad. Phys. Chem. 175 (2020) 108100.

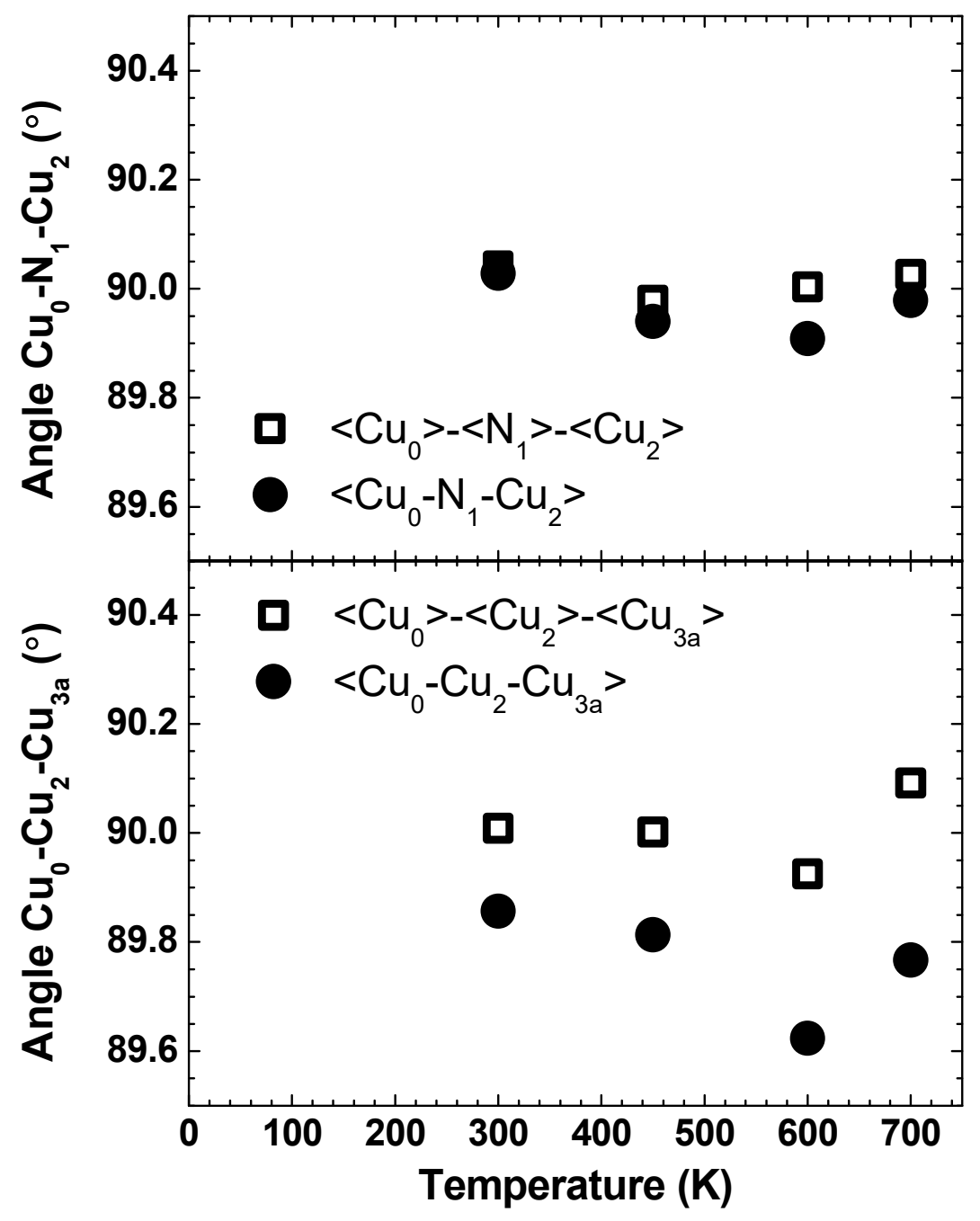

Figure 6: Temperature dependencies of the $\mathrm{Cu}_{0}-\mathrm{N}_{1}-\mathrm{Cu}_{2}$ and $\mathrm{Cu}_{0}-\mathrm{Cu}_{2}-\mathrm{Cu}_{3 a}$ bond angle values in $\mathrm{Cu}_{3} \mathrm{~N}$ system. Open squares are angles between the average positions of atoms, whereas solid circles correspond to the average angles. 
D. Bocharov, A. Anspoks, J. Timoshenko, A. Kalinko, M. Krack, A. Kuzmin,

Interpretation of the Cu K-edge EXAFS spectra of Cu3N using ab initio molecular dynamics, Rad. Phys. Chem. 175 (2020) 108100.

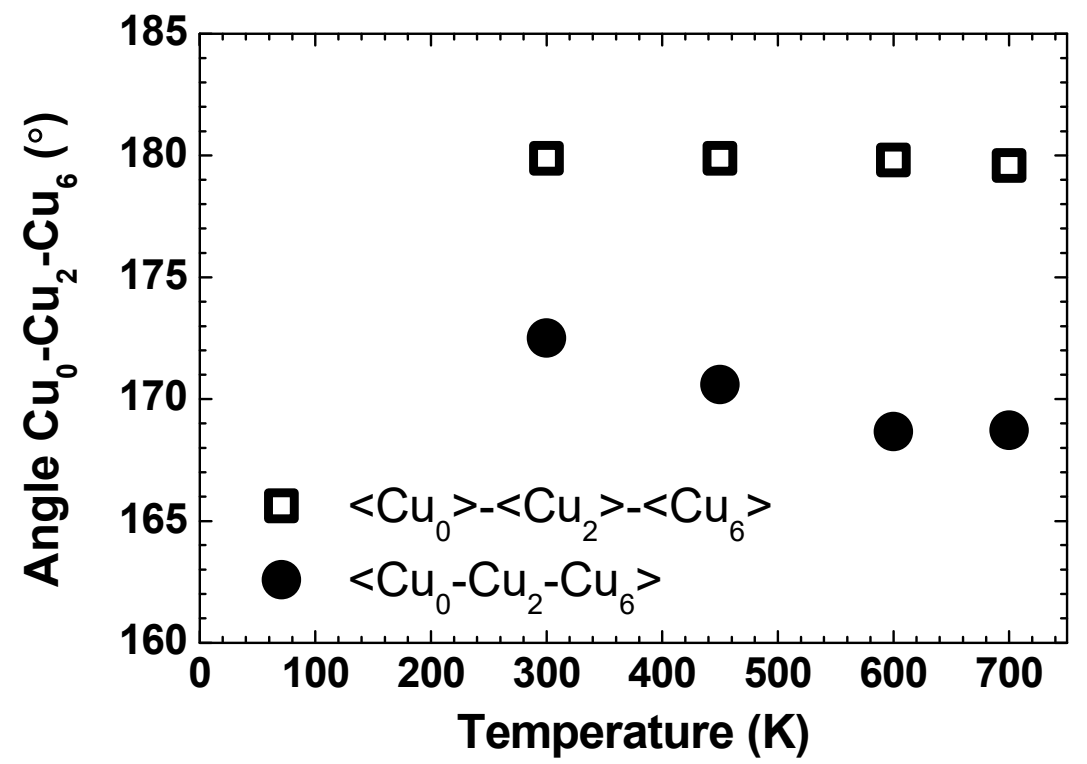

Figure 7: Temperature dependencies of the $\mathrm{Cu}_{0}-\mathrm{Cu}_{2}-\mathrm{Cu}_{6}$ bond angle values in for atoms in in $\mathrm{Cu}_{3} \mathrm{~N}$ system. Open squares are angles between the average positions of atoms, whereas solid circles correspond to the average angles.

Institute of Solid State Physics, University of Latvia as the Center of Excellence has received funding from the European Union's Horizon 2020 Framework Programme H2020-WIDESPREAD-01-2016-2017-TeamingPhase2 under grant agreement No. 739508, project CAMART² 